\title{
Article \\ Physiological and Biochemical Evaluation of Different Types of Recovery in National Level Paralympic Powerlifting
}

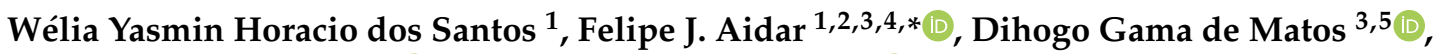 \\ Roland Van den Tillaar ${ }^{6}{ }^{\circ}$, Anderson Carlos Marçal ${ }^{1,3}{ }^{\mathbb{D}}$, Lázaro Fernandes Lobo ${ }^{7}$, \\ Lucas Soares Marcucci-Barbosa ${ }^{7}$, Saulo da Cunha Machado ${ }^{8}$ (D) Paulo Francisco de Almeida-Neto ${ }^{9}$, \\ Nuno Domingos Garrido ${ }^{10}{ }^{\oplus}$, Victor Machado Reis ${ }^{10}$, Érica Leandro Marciano Vieira ${ }^{11}$, \\ Breno Guilherme de Araújo Tinoco Cabral ${ }^{9}{ }^{\circledR}$, José Vilaça-Alves ${ }^{10}{ }^{\infty}$, Albená Nunes-Silva ${ }^{7}$ \\ and Walderi Monteiro da Silva Júnior ${ }^{1,12}$
}

check for updates

Citation: Santos, W.Y.H.d.; Aidar, F.J.; Matos, D.G.d.; Van den Tillaar, R.; Marçal, A.C.; Lobo, L.F.; Marcucci-Barbosa, L.S.; Machado, S.d.C.; Almeida-Neto, P.F.d.; Garrido, N.D.; et al. Physiological and Biochemical Evaluation of Different Types of Recovery in National Level Paralympic Powerlifting. Int. J. Environ. Res. Public Health 2021, 18, 5155. https://doi.org/10.3390/ ijerph18105155

Academic Editor: Paul B. Tchounwou

Received: 21 April 2021

Accepted: 11 May 2021

Published: 13 May 2021

Publisher's Note: MDPI stays neutral with regard to jurisdictional claims in published maps and institutional affiliations.

Copyright: (C) 2021 by the authors Licensee MDPI, Basel, Switzerland. This article is an open access article distributed under the terms and conditions of the Creative Commons Attribution (CC BY) license (https:// creativecommons.org/licenses/by/ $4.0 /)$
1 Graduate Program in Physical Education, Federal University of Sergipe (UFS), São Cristovão 49100-000, Sergipe, Brazil; weliaa@hotmail.com (W.Y.H.d.S.); acmarcal@yahoo.com.br (A.C.M.); walderim@yahoo.com.br (W.M.d.S.J.)

2 Department of Physical Education, Federal University of Sergipe (UFS), São Cristovão 49100-000, Sergipe, Brazil

3 Group of Studies and Research of Performance, Sport, Health and Paralympic Sports_-GEPEPS, The Federal University of Sergipe (UFS), São Cristovão 49100-000, Sergipe, Brazil; dihogogmc@hotmail.com

4 Graduate Program of Physiological Science, Federal University of Sergipe-UFS, São Cristovão 49100-000, Sergipe, Brazil

5 Cardiovascular \& Physiology of Exercise Laboratory, University of Manitoba, Winnipeg, MB R3T 2N2, Canada

6 Department of Sport Sciences and Physical Education, Nord University, 7600 Levanger, Norway; roland.v.tillaar@nord.no

7 Laboratory of Inflammation and Exercise Immunology, Sports Center, Federal University of Ouro Preto, Ouro Preto 35400-000, Minas Gerais, Brazil; lobocav@hotmail.com (L.F.L.); lucasmarcucci@gmail.com (L.S.M.-B.); albenanunes@hotmail.com (A.N.-S.)

8 Graduate Program in Health Science, Federal University of Sergipe (UFS), São Cristovão 49100-000, Sergipe, Brazil; saulo0407@gmail.com

9 Department of Physical Education, Federal University of Rio Grande do Norte, Lagoa Nova 59078-970, Natal, Brazil; paulo220911@hotmail.com (P.F.d.A.-N.); brenotcabral@gmail.com (B.G.d.A.T.C.)

10 Research Center in Sports Sciences, Health Sciences and Human Development (CIDESD), Trás os Montes and Alto Douro University, 5000-801 Vila Real, Portugal; ngarrido@utad.pt (N.D.G.); victormachadoreis@gmail.com (V.M.R.); josevilaca@utad.pt (J.V.-A.)

11 Interdisciplinary Medical Research Laboratory (LIIM), Faculty of Medicine, Federal University of Minas Gerais, Belo Horizonte 30130-100, Minas Gerais, Brazil; ericalmvieira@gmail.com

12 Department of Physical Therapy, Universitary Hospital, Federal University of Sergipe (UFS), São Cristovão 49100-000, Sergipe, Brazil

* Correspondence: fjaidar@gmail.com; Tel.: +55-799-9685-7777

Abstract: Background: Recovery from training is vital as it ensures training and performance to continue at high intensities and longer durations to stimulate the body and cause further adaptations. Objective: To evaluate different methods of post-workout recovery in Paralympic powerlifting athletes. Methods: Twelve male athletes participated ( $25.4 \pm 3.3$ years; $70.3 \pm 12.1 \mathrm{~kg})$. The presence of muscle edema, pain threshold, plasma cytokines, and performance measurement were evaluated five times. The recovery methods used in this study were passive recovery (PR), dry needling (DN), and cold-water immersion (CWI). Results: The data analysis showed that the maximal force decreased compared to the pretest value at $15 \mathrm{~min}$ and $2 \mathrm{~h}$. The results also revealed that CWI and DN increased Interleukin 2 (IL-2) levels from 24 to $48 \mathrm{~h}$ more than that from $2 \mathrm{~h}$ to $24 \mathrm{~h}$. After DN, muscle thickness did not increase significantly in any of the muscles, and after $2 \mathrm{~h}$, muscle thickness decreased significantly again in the major pectoralis muscle. After CWI, pain pressure stabilized after $15 \mathrm{~min}$ and increased significantly again after $2 \mathrm{~h}$ for acromial pectoralis. Conclusion: The strength training sessions generate several changes in metabolism and different recovery methods contribute differently to maintain homeostasis in Paralympic powerlifting athletes. 
Keywords: Paralympic powerlifting; plasma cytokines; recovery; cold water immersion; dry needling

\section{Introduction}

Post-exercise recovery has been the focus of intensive investigation in the scientific community because of its importance in current physical training programs at different performance levels, especially at the high levels of performance at which the athletes train more than once a day [1,2]. The adequate post-exercise recovery strategy is an essential aspect of any physical conditioning program [3-5] and consists of restoring the body's systems to their basal conditions [4].

Monitoring of post-exercise recovery is important to ensure better quality in all subsequent training sessions. The inadequacy between volume and intensity in training sessions and rest periods can go beyond the individual limit of athletes, resulting in unnecessary wear and tear [6]. Therefore, it is necessary to give equal importance to both training and recovery before submitting the athlete to a new training session or competition to maintain a healthy balance, avoid performance restriction, and decrease injury risk [4].

Several recovery methods have been proposed, such as stretching, massage, cryotherapy, relaxation techniques, thermotherapy, and physiotherapy techniques [7]. These recovery methods must work daily and allow for quick access to selected markers, providing immediate feedback of the subject's psychophysical condition, leading to interventions in training loads and performance improvements [7].

Cold water immersion (CWI) is commonly used to relieve pain, particularly inflammatory diseases, injuries, and overuse [8]. Furthermore, recovery in post-workout CWI in athletes has been widely used, with positive effects on physiological aspects, the inflammatory process, and metabolic and nerve transmission [9-11]. Cooling the body to accelerate recovery decreases muscle damage and inflammation markers [8]. CWI involves submersing a part of or the whole body, except the head, in a cold-water bath (11 to $\left.15^{\circ} \mathrm{C}\right)$ for 11 to $15 \mathrm{~min}[12,13]$. However, although athletes have widely used CWI, this type of recovery is not yet used in Paralympic athletes due to the fact that these athletes have difficulties in being inserted/removed from the place of the recovery process.

In addition, the use of dry needling $(\mathrm{DN})$ in recovery has been proposed to reduce muscle pain $[14,15]$. This technique acts through a local inflammatory process by increasing blood supply to the injured area. However, there are no reports of its application to alleviate late muscle pain symptoms [14,15]. Dry needling is a relatively new technique for recovery, which already shows good results in recovery overuse, which is common in sports [16].

The literature proposes some recovery methods for athletes, including CWI [17], non-steroidal anti-inflammatory drugs (NSAIDs) (i.e., ibuprofen) [18], and dietary supplements $[19,20]$. Furthermore, there is a paucity of scientific information on the effects of post-exercise recovery methods on Paralympic powerlifting athletes. Therefore, we aim to evaluate the effects of different post-training recovery methods on mechanical, biochemical, and pain scales in Paralympic powerlifting athletes. Because of this lack of consensus on post-exercise recovery and the difficulty Paralympic athletes have performing a recovery in immersion in cold water, it was hypothesized that DN could be effective in post-exercise recovery in Paralympic athletes. In addition, other recovery techniques have been shown to be just as effective for athletes, which could be tested for Paralympic athletes.

\section{Materials and Methods}

The study was conducted over 4 weeks; in the first week, the athletes were familiarized with the tests and in the second to fourth weeks, different recovery methods were evaluated. The recovery methods evaluated included passive recovery (PR), dry needling (DN), and cryotherapy recovery (Figure 1). 


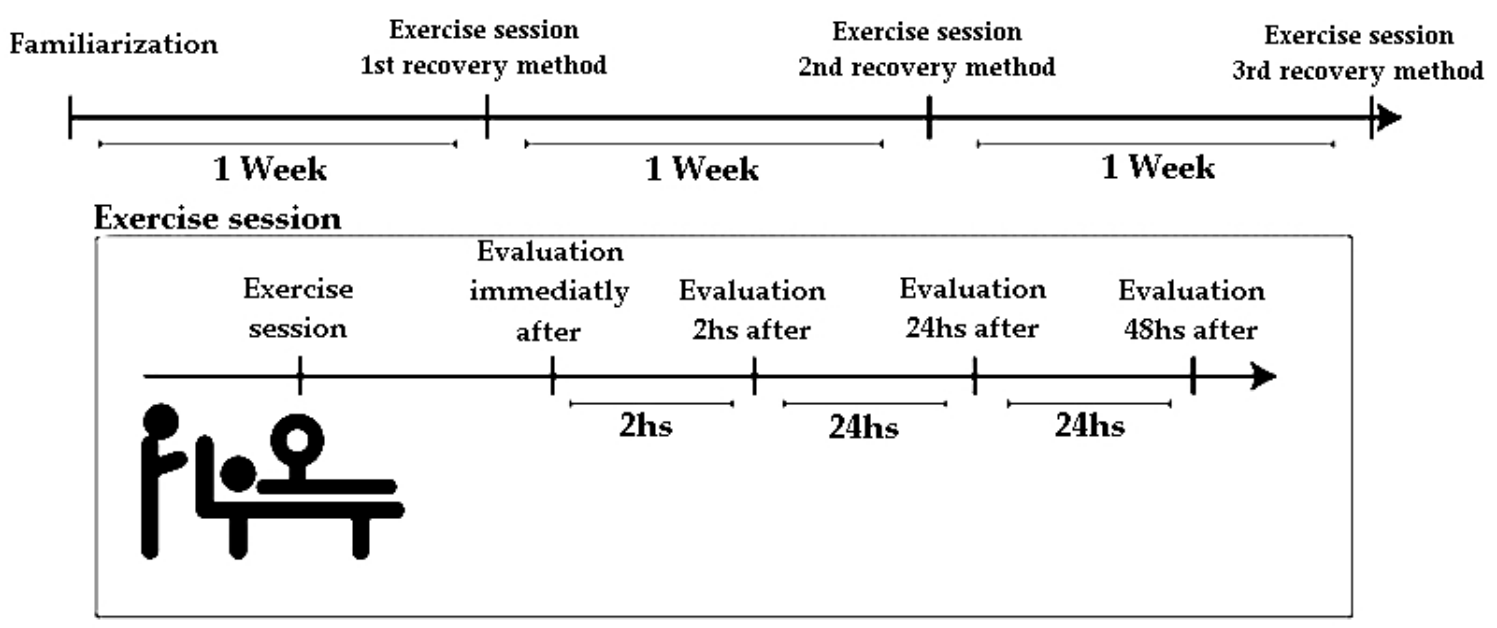

Recovery methods
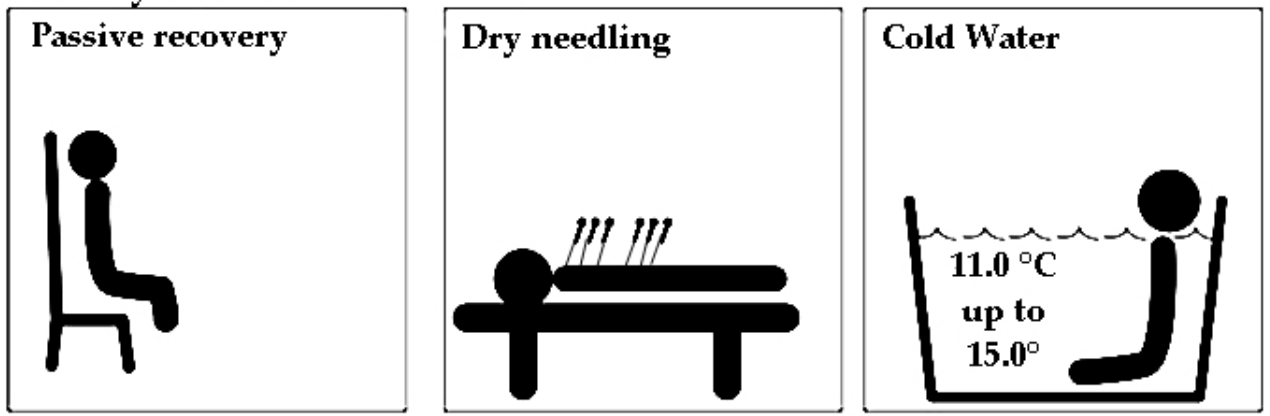

Figure 1. Outline of the research: summary of the study. The athletes in three types of recovery methods: passive, dry needling, and cryotherapy. The recovery methods were evaluated in four stages: immediately, $2 \mathrm{~h}, 24 \mathrm{~h}$, and $48 \mathrm{~h}$ after the end of the session.

\subsection{Sample}

This was a cross-over study involving 12 male Paralympic powerlifting athletes (age: $25.4 \pm 3.3$ years; body mass: $70.3 \pm 12.2 \mathrm{~kg} ; 1$ repetition maximum (RM): $117.4 \pm 23.4 \mathrm{~kg}$; $1 \mathrm{RM}$ /body mass: $1.67 \pm 0.28$ ). Those who were clinically stable and had been practicing the sport for at least 12 months ( $2.5 \pm 0.2$ years), eligible for Paralympic powerlifting, were included. Inclusion criteria also involved those who had participated in an official competition in the past 6 months, were eligible for the sport in accordance with the rules of the International Paralympic Committee (IPC) [21], had been training uninterruptedly for at least 12 months, and were ranked among the top 10 of their respective categories at the national level. The exclusion criteria were not participating in any of the evaluations and making use of any type of legal or illegal ergogenic.

All participants were national-level athletes; two national champions, two runners-up, and two third places. The rest were classified in the top 10 of their respective categories, according to the criteria of the International Paralympic Committee [21]. Regarding disability types, four athletes presented spinal cord injury due to trauma, with injury below the eighth thoracic vertebra; two with sequelae due to polio; four with lower limb malformation (arthrogryposis); and two with cerebral palsy.

This study was approved by the Human Research Ethics Committee of the Federal University of Sergipe (UFS), CAEE: 79909917.0.0000.55.46 (technical advice: 2,637,882, date of approval: 7 May 2018). The procedures adopted followed the standards of ethics in research with humans per Resolution No. 466, of 12 December 2012, which are the guidelines and regulatory standards for research involving humans, in accordance with the ethical principles contained in the Declaration of Helsinki (1964, restated in 1975, 1983, 1989, 1996, 2000, 2008, and 2013) of the "World Medical Association." 


\subsection{Procedures}

One familiarization session in the 2 weeks and at least $72 \mathrm{~h}$ before the intervention was conducted. The $1 \mathrm{RM}$ test was performed, in which, initially, the subjects performed the trials with a weight that they estimated could be lifted only once, using the maximum effort. Weight was then added until the maximum load that could be lifted with one repetition was reached. If the participant could not perform a single repetition, $2.4-2.5 \%$ of the load used in the test was subtracted [22]. A 3- to 5-min rest was provided between attempts. The minimum interval between tests and the beginning and end of the training session was $10 \mathrm{~min}$.

On the intervention days, the athletes performed a warm-up for the upper limbs, using three exercises (abduction of the shoulders with dumbbells, elbow extension in the pulley, and rotation of the shoulders with dumbbells), with three sets of 10 to $20 \mathrm{RM}$ in approximately $10 \mathrm{~min}$ [21]. Subsequently, a specific warm-up was performed on the bench press itself, with $30 \%$ of the load for $1 \mathrm{RM}$, in which 10 slow repetitions (3:1 s: eccentric $\times$ concentric) and 10 fast repetitions (1:1 s), controlled with a Willner metronome (Willner, Isny, Germany), were performed to induce muscle damage. During the test, the athletes were verbally encouraged to perform the movement with their best performance [23].

The bench press movement was used, and five sets of five repetitions with a load of $120 \%$ in the eccentric phase and $80 \%$ in the concentric phase of $1 \mathrm{RM}$ and three additional series of five repetitions, with emphasis on acceleration with a $40 \%$ load of $1 \mathrm{RM}$, were performed. In the five initial repetitions, an extra load was placed in the eccentric phase, which was removed in the concentric phase, making up $120 \%$ of $1 \mathrm{RM}$ in the eccentric phase and $80 \%$ in the concentric phase. In the three additional repetitions, only $80 \%$ of $1 \mathrm{RM}$ was used, while, in the concentrated phase, an evaluator helped the athletes complete three repetitions. Technical training involved the use of loads previously determined for each individual in the maximum repetition test (1 RM). Between the exercise blocks, a 3-min interval for rest was provided.

After the exercise-induced muscle damage, one of the recovery methods was applied, and $10 \mathrm{~min}$ of rest were provided without any specific protocol [24]. The athletes remained seated before performing one of the recovery methods. The recovery methods were defined by lot, where $1 / 3$ of the athletes did each recovery method in turn in three sessions until they completed the three recovery methods.

A trained physiotherapist performed the $\mathrm{DN}$ technique and explained how it works and how sensations, such as "pinching", can be perceived during the application due to the stimulus and muscle response. The application site was sterilized using cotton soaked in $70 \%$ alcohol, then the individual was placed in the supine position when directing the pectoralis major (between the third and fourth intercostal space under the midpoint of the clavicle, anterior deltoid (upper, anterior, and 1/3 lateral the clavicle to the deltoid tuberosity of the humerus), and in the lateral decubitus when directing the brachial triceps (60\% distal between the lateral epicondyle of the humerus and the scapular acromial process), where the needle applications were performed by means of stainless and sterile monofilament $(0.25 / 40 \mathrm{~mm})$, perpendicular to the muscles and held in place for $5 \mathrm{~min}$, not being manipulated or stimulated during the execution of the in situ technique.

According to the criteria established by the study, this technique offers minimal risks to individuals; however, in individuals with a low pain threshold, this stimulus can be painful [25].

In the CWI intervention, the athletes stayed immersed for $15 \mathrm{~min}$ in cold water up to their neck $\left(11.0^{\circ} \mathrm{C}\right.$ up to $\left.15.0^{\circ} \mathrm{C}\right)$, following the protocol defined by Machado et al. [12] and Vieira et al. [13].

In the passive recovery method, the athletes remained seated for 15 min without any activities. The intervention order was carried out by drawing lots, where $1 / 3$ made a recovery in each method. 


\subsection{Instruments/Measurements}

Measurements were taken before and immediately after each recovery method $( \pm 15 \mathrm{~min}$ after the exercise-induced muscle damage) and after 2, 24, and $48 \mathrm{~h}$ (Figure 1). The pressure pain threshold (PPT) was assessed using a digital pressure algometer $\left(\operatorname{Impac}{ }^{\circledR}\right.$, probe with an area of $1.0 \mathrm{~cm}^{2}$, São Paulo, SP, Brazil). The instrument was placed perpendicular to the pectoralis major, anterior deltoid, and triceps on each muscle's motor point, following the anatomical references used in the ultrasound measurements [26].

The evaluator placed continuous pressure on the musculature, and the athletes were instructed to say "stop" when the sensation of pressure became painful. Three measurements were taken for each muscle, and each muscle's average was recorded [27].

\subsection{Ultrasound}

To measure muscle thickness after exercise, an ultrasound device (Medison Sonoace ${ }^{\circledR}$ brand, General Electric, Boston, MA, USA) was applied to the respective muscles: pectoral and deltoid [26].

Before the tests, each musculature's measuring points were marked with a felt-tip pen for better identification of the structures. The individuals remained with their muscles relaxed in order not to generate interference in the measurement. The head of the device was used to make a 5-MHz scan with a linear-type transducer in the measurement sites without pressing the tissue, identifying the adipose tissue's subcutaneous connections and the muscle-bone interface, for which distances were measured, corresponding to the muscle thickness. The device provided the measurement through which the ultrasound images were frozen and the measurements were extracted [28].

\subsection{Blood Biochemical Indicators}

The blood of the individuals participating in the study was collected by qualified health professionals, respecting biosafety techniques, such as the use of gloves and sterile and disposable material. About $30 \mathrm{~mL}$ of blood was collected using tubes with heparin, EDTA, and clot activator and sterile and disposable material (Vacutainer, Grand Island, NY, USA). According to the manufacturer's instructions, the serum blood concentrations of plasma cytokine were measured using the cytometric bead array (CBA) method, with Human T helper (Th) (Th1/Th2 Cytokine Kit II: brand BD Biosciences, San Jose, CA, USA). These kits were used to quantify inflammatory protein cytokines interleukin (IL), IL-2, and IL-4 and interferon gama (IFN- $\gamma$ ). The plasma samples were incubated, with the capture microspheres covered by specific antibodies for the respective cytokines and chemokines, as well as the proteins of the standard curve. The color reagent (Ficoeritrina: PE) was added to the samples before being incubated for $3 \mathrm{~h}$. After incubation, the samples were washed (Wash buffer ${ }^{\circledR}$ ) and centrifuged (1100 rpm, 200 $\times g$ per $5.0 \mathrm{~min}$, room temperature). The supernatant was discarded, and the precipitate containing the microspheres was resuspended with $300 \mu \mathrm{L}$ of Wash buffer.

The samples were analyzed using the BD FACS Canto II flow cytometer (Becton \& Dickinson, San Jose, CA, USA). The results were analyzed using the FCAP software (BD Bioscience, San Jose, CA, USA) and are represented in $\mathrm{pg} / \mathrm{mL}$. The blood was stored in a $-80{ }^{\circ} \mathrm{C}$ freezer.

IL-2 has a pro-inflammatory action and helps in the proliferation of T and B lymphocytes, inducing the production of IFN- $\gamma$ [29]. IFN- $\gamma$ has a pro-inflammatory action, activating Macrophage to produce toxic radicals and TNF- $\alpha$ production, which in turn has a pro-inflammatory action, inducing IL-1 shock protein and apoptosis [29-31]. IL-4 has an anti-inflammatory action, inhibiting the production of IL- $1 \alpha / \beta$, tumor necrosis factor alpha (TNF- $\alpha$ ), and IL-6, and inducing Th0-Th2 differentiation and proliferation and differentiation of B lymphocytes [27]. 


\subsection{Maximum Isometric Force}

The maximum isometric force (MIF) was determined using a Musclelab force sensor (Model PFMA 3010e MuscleLab System; Ergotest, Langesund, Norway) attached to the adapted Bench, employing Spider HMS Simond carabiners (Chamonix, France) with a $21 \mathrm{KN}$ burst load, approved for climbing by the Union Internationale DES Associations d'Alpinisme (UIAA). A steel chain with a breaking load of $2300 \mathrm{~kg}$ was used to fix the bench's force sensor. The perpendicular distance between the force sensor and the joint center was determined and used to calculate joint torques, adapted from the procedure performed by Fraga et al. [18] and Sampaio et al. [19].

The isometric force was determined by a force sensor attached to an inextensible cable and the adapted bench press. Participants were instructed to perform a single maximum movement, looking for elbow extension $\left(90^{\circ}\right)$ ("as fast as possible") and to relax.

\subsection{Statistics}

For the descriptive analysis, central tendency measures, average $(X) \pm$ standard deviation (SD), were used. The normality of the variables was tested using the ShapiroWilk test. Because significant differences were found at the baseline between the different recovery methods, a 3 (recovery method) $\times 4$ (test time: pre- $15 \mathrm{~min}, 15 \mathrm{~min}$ to $2 \mathrm{~h}, 2-24 \mathrm{~h}$, and 24-48 h) analysis of variance (ANOVA test) with repeated measures on each variable with the baseline data as a covariate was performed, with Holm-Bonferroni's post-hoc test. The effect size was determined by the values of "partial eta squared" $\left(\eta^{2} p\right)$, considering values of low effect $(\leq 0.05)$, medium effect $(0.05-0.25)$, high effect $(0.25-0.50)$, and very high effect $(>0.50)$ [32]. The percentage of the variation coefficient $(\mathrm{CV} \%)$ was calculated for the variables using the formula: $\mathrm{CV} \%=($ standard deviation $(\mathrm{SD}) /$ mean $) \times 100$. To measure the reliability between the measurements by different methods (Passive, DN, and $\mathrm{CW}$ )], we calculated the intraclass correlation coefficient (ICC), whose magnitudes were determined [32]: absence: $<0$; bad: $0-0.19$; weak: $0.20-0.39$; moderate: $0.30-0.59$; substantial: $0.60-0.79$; almost complete: $\geq 0.80$. Statistical analyses were performed using the Statistical Package for the Social Science (SPSS) version 25.0 software (IBM, North Castle, New York, NY, USA). The level of significance was set at $p<0.05$.

\section{Results}

A significant effect of the recovery method $\left(\mathrm{F}=3.6, p=0.046 ; \eta^{2} \mathrm{p}=0.25\right)$, test occasion $\left(\mathrm{F}=6.7, p=0.001 ; \eta^{2} \mathrm{p}=0.38\right)$, and method $\times$ test interaction $\left(\mathrm{F}=7.1, p=0.002 ; \eta^{2} \mathrm{p}=0.39\right)$ were found for MIF. Post-hoc comparison revealed that maximal force decreased from pretest to straight after implementation of the different recovery methods. Both PR and DN increased to the baseline levels of MIF from 2 to $24 \mathrm{~h}$, whereas CWI increased MIF from 2 to 24 , but reached $20 \%$ more force after $24 \mathrm{~h}$ than at the baseline level (Figure 2).

In relation to Figure 2, the $\% \mathrm{CV}$ for MIF were: passive recovery: pre-test $=37.7 \%$; after 15 min: $26.2 \%$; after $24 \mathrm{~h}: 24.6 \%$; after $48 \mathrm{~h}: 30.0 \%$. In DN recovery: pre-test $=33.3 \%$; after 15 min: $22.5 \%$; after $24 \mathrm{~h}: 24.7 \%$; after $48 \mathrm{~h}: 23.1 \%$. With regard to the CWI recovery: pre-test $=31.1 \%$; after $15 \mathrm{~min}: 18.8 \%$; after $24 \mathrm{~h}: 16.5 \%$; after $48 \mathrm{~h}: 29.2 \%$. In addition, for MIF, the ICC among the recovery methods (passive, DN, and CWI) was: pre-test: ICC $=0.95$ (95\% CI: 0.87; 0.99, $p<0.0001)$; after $15 \mathrm{~min}:$ ICC $=0.76$ (95\% CI: 0.43; 0.94, $p<0.0001)$; after 24 h: ICC $=0.47$ (95\% CI: $0.04 ; 0.84, p=0.01)$; after 48 h: ICC $=0.40(95 \%$ CI: $-0.02 ; 0.80, p=0.03)$. 


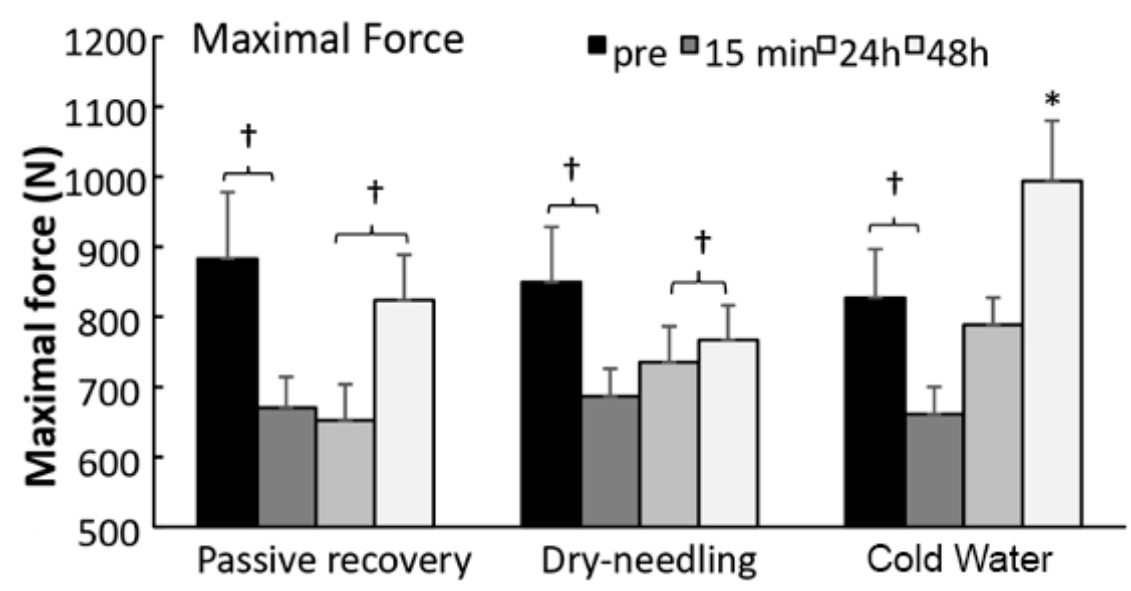

Figure 2. Maximal isometric force measured in the bench press before and after $15 \mathrm{~min}, 2 \mathrm{~h}, 24 \mathrm{~h}$, and $48 \mathrm{~h}$ after an exercise induces muscle damage and a recovery (passive, dry-needling, or cold-water immersion) protocol after $15 \mathrm{~min}, 24 \mathrm{~h}$, and $48 \mathrm{~h}$ after exercise-induced muscle damage and a recovery protocol. * indicates a significant difference with all other test moments $(p<0.05)$. † indicates a significant difference between these two test moments $(p<0.05)$.

Only a significant effect of the recovery method $\left(\mathrm{F}=7.1, p<0.006 ; \eta^{2} \mathrm{p}=0.47\right)$ and over moments $\left(\mathrm{F}=6.0, p<0.003 ; \eta^{2} \mathrm{p}=0.43\right)$ in biochemical blood indicators was found in IL-2. Post-hoc comparison revealed that CWI and DN increased IL-2 levels from 24 to $48 \mathrm{~h}$ more than that from 2 to $24 \mathrm{~h}$, whereas the other two did not change significantly over time (Figure 3).

In relation to Figure 3, for passive recovery, the $\% \mathrm{CV}$ of the variables were: IFN- $\gamma$ : pre-test $=31.8 \%$; after $15 \mathrm{~min}: 26.2 \%$; after $2 \mathrm{~h}: 30.6 \%$; after $24 \mathrm{~h}: 16.6 \%$; after $48 \mathrm{~h}: 22.7 \%$. IL-4: pre-test $=21.1 \%$; after 15 min: $20.2 \%$; after 2 h: $10.9 \%$; after 24 h: $14.9 \%$; after 48 h: $12.4 \%$. IL2: pre-test $=22.4 \%$; after $15 \mathrm{~min}: 18.7 \%$; after $2 \mathrm{~h}: 17.2 \%$; after $24 \mathrm{~h}: 14.7 \%$; after 48 h: $13.4 \%$.

For DN recovery, the $\% \mathrm{CV}$ of the variables were: $\mathrm{IFN}-\gamma$ : pre-test $=29.7 \%$; after $15 \mathrm{~min}$ : $31.5 \%$; after 2 h: $29.5 \%$; after 24 h: $27.4 \%$; after 48 h: $24.8 \%$. IL-4: pre-test $=20.5 \%$; after 15 min: $23.0 \%$; after 2 h: $17.1 \%$; after 24 h: $15.5 \%$; after 48 h: $18.6 \%$. IL2: pre-test $=12.7 \%$; after $15 \mathrm{~min}: 18.8 \%$; after $2 \mathrm{~h}: 17.0 \%$; after $24 \mathrm{~h}: 16.9 \%$; after $48 \mathrm{~h}: 16.3 \%$.

For the CWI recovery, the $\% \mathrm{CV}$ of the variables were: IFN- $\gamma$ : pre-test $=25.5 \%$; after $15 \mathrm{~min}: 33.9 \%$; after $2 \mathrm{~h}: 28.1 \%$; after $24 \mathrm{~h}: 26.0 \%$; after 48 h: $24.8 \%$. IL-4: pre-test $=27.0 \%$; after 15 min: $22.5 \%$; after $2 \mathrm{~h}: 23.2 \%$; after $24 \mathrm{~h}: 32.2 \%$; after 48 h: $20.1 \%$. IL2: pre-test $=20.5 \%$; after 15 min: $17.2 \%$; after 2 h: $18.3 \%$; after 24 h: $26.1 \%$; after 48 h: $21.0 \%$.

In Figure 3, the ICC among the recovery methods (passive, DN, and CWI) for cytokines: IFN- $\gamma$ : pre-test: ICC $=0.58$ (95\% CI: $0.17 ; 0.88, p=0.002)$; after $15 \mathrm{~min}$ : ICC $=0.74(95 \%$ CI: $0.39 ; 0.93, p=0.0001)$; after 2 h: ICC $=0.56$ (95\% CI: 0.15; 0.87, $p=0.003)$; after 24 h: ICC $=0.18$ (95\% CI: $-0.19 ; 0.68, p=0.1)$; after 48 h: ICC $=0.20(95 \%$ CI: $-0.17 ; 0.70, p=0.1)$. IL-4: pretest: ICC $=0.16(95 \%$ CI: $-0.20 ; 0.67, p=0.2)$; after $15 \mathrm{~min}:$ ICC $=0.31(95 \%$ CI: $-0.06 ; 0.78, p=0.05)$; after 2 h: ICC $=0.14(95 \%$ CI: $-0.21 ; 0.66, p=0.2)$; after $24 \mathrm{~h}$ : ICC $=0.58$ (95\% CI: $0.16 ; 0.88, p=0.003)$; after 48 h: ICC $=0.18(95 \%$ CI: $-0.18 ; 0.69, p=0.1)$. IL2: pretest: CCI $=0.32$ (95\% CI: $-0.09 ; 0.76, p=0.06)$; after $15 \mathrm{~min}$ : ICC $=0.78$ (95\% CI: 0.48 ; $0.94, p<0.0001)$; after 2 h: ICC $=0.81$ (95\% CI: 0.52; 0.95, $p<0.0001)$; after 24 h: ICC $=0.74$ (95\% CI: $0.40 ; 0.93, p<0.0001)$; after 48 h: ICC $=0.32$ (95\% CI: $-0.09 ; 0.76, p=0.06)$. 


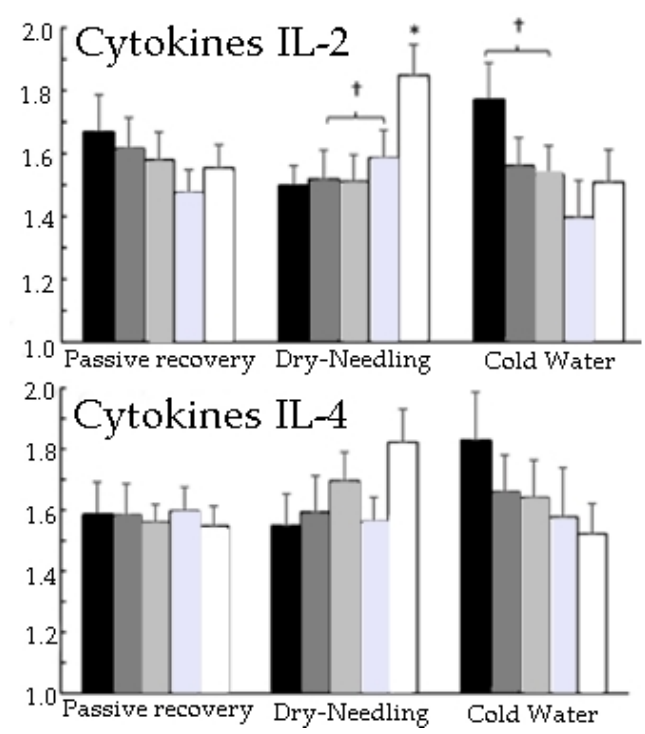

- Pre $\square 15 \min \square 2 \mathrm{~h}$

$\square 24 \mathrm{~h} \square 48 \mathrm{~h}$

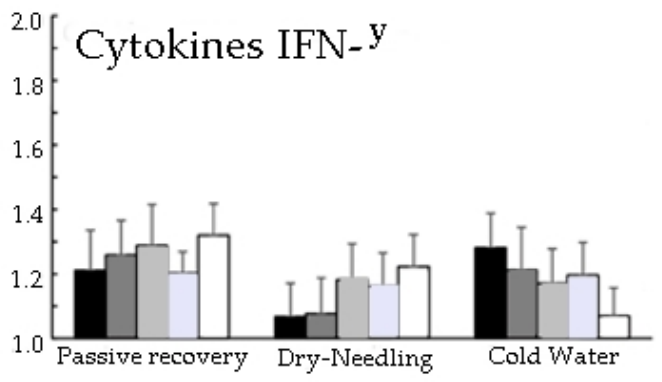

Figure 3. Mean $( \pm \mathrm{SEM})$ differences in blood biochemical indicators (Cytokines IL-2, IL-4, and IFN- $\gamma$ ). Before and after $15 \mathrm{~min}, 2 \mathrm{~h}, 24 \mathrm{~h}$, and $48 \mathrm{~h}$ exercise-induced muscle damage and recovery (passive, dry-needling, or cold-water immersion) protocol. Cytokines IL-2, IL-4 e, and IFN- $\gamma$ (pg/mL). * indicates a significant difference with all other test occasions $(p<0.05)$. + indicates a significant difference between these two test occasions $(p<0.05)$.

A significant effect of recovery method $\left(\mathrm{F}=8.9, p \leq 0.002 ; \eta^{2} \mathrm{p}=0.52\right)$, test occasion $\left(\mathrm{F}=5.8, p \leq 0.001 ; \eta^{2} \mathrm{p}=0.42\right)$, and interaction effect $\left(\mathrm{F}=7.1, p<0.001 ; \eta^{2} \mathrm{p}=0.47\right)$ on muscle thickness was noted. Post-hoc comparisons revealed that muscle thickness increased mostly after PR in all muscles and remained elevated, whereas, after cryotherapy, only muscle thickness was significantly higher after $15 \mathrm{~min}$ and $2 \mathrm{~h}$. After DN, muscle thickness did not increase significantly in any of the muscles and, after $2 \mathrm{~h}$ muscle thickness, decreased significantly again in the major pectoralis muscle (Figure 4).

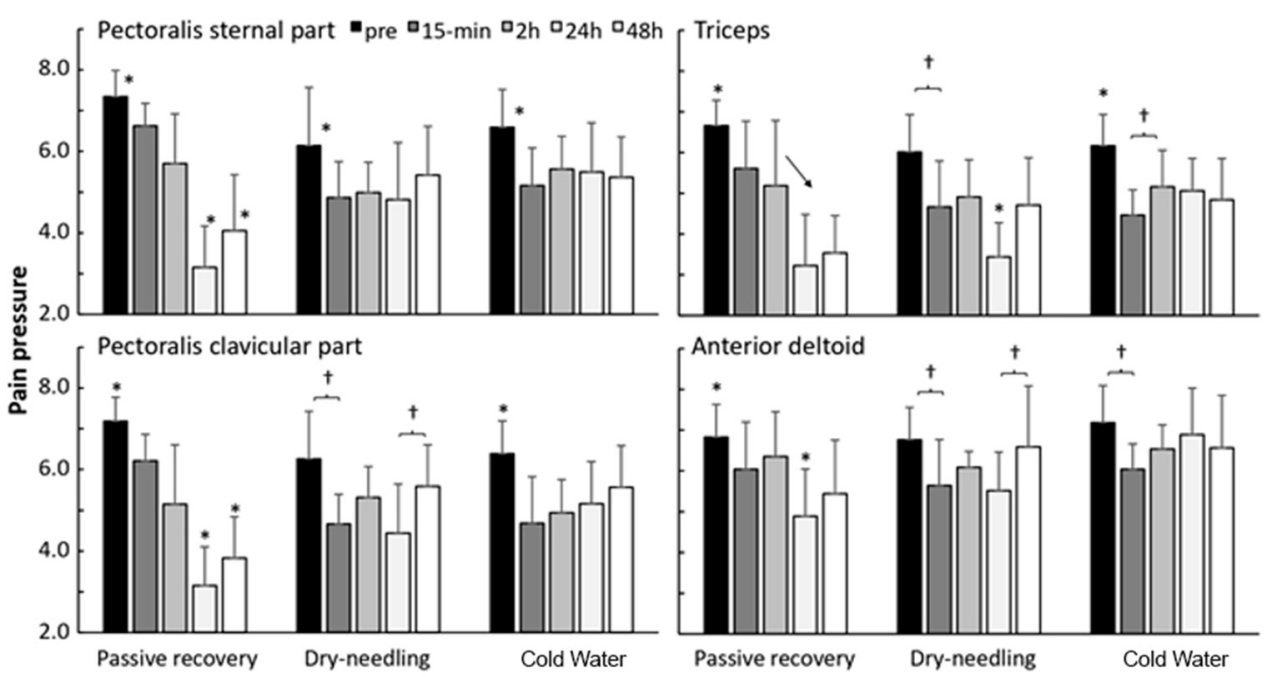

Figure 4. Mean $( \pm$ SEM) differences in pain pressure before and after $15 \mathrm{~min}, 2 \mathrm{~h}, 24 \mathrm{~h}$, and $48 \mathrm{~h}$ exercise-induced muscle damage and recovery (passive, dry-needling, or cold-water immersion) protocol for triceps, pectoralis clavicular and sternal part, and anterior deltoid muscles. Pressure values $\left(\mathrm{kg} / \mathrm{cm}^{2}\right)$. * indicates a significant difference with all other test occasions $(p<0.05) .+$ indicates a significant difference between these two test occasions. $(p<0.05)$ indicates a significant change between these test moments for this protocol on a $p<0.05$ level. 
In relation to Figure 4, for passive recovery, the $\% \mathrm{CV}$ of the variables were: external chest: pre-test $=7.9 \%$; after $15 \mathrm{~min}: 6.9 \%$; after $2 \mathrm{~h}: 21.6 \%$; after $24 \mathrm{~h}: 31.5 \%$; after $48 \mathrm{~h}$ : $34.2 \%$. Clavicular pectoralis: pre-test $=7.0 \%$; after $15 \mathrm{~min}: 9.5 \%$; after $2 \mathrm{~h}: 28.7 \%$; after $24 \mathrm{~h}$ : $29.2 \%$; after 48 h: $25.9 \%$. Triceps: pre-test $=8.2 \%$; after $15 \mathrm{~min}$ : $12.2 \%$; after $2 \mathrm{~h}: 31.5 \%$; after 24 h: $38.6 \%$; after 48 h: $24.9 \%$. Deltoid: pre-test $=11.2 \%$; after 15 min: 19.3\%; after 2 h: $17.3 \%$; after 24 h: $23.6 \%$; after 48 h: $24.6 \%$.

For the DN recovery, the $\% \mathrm{CV}$ of the variables were: external chest: pre-test $=23.7 \%$; after 15 min: $17.6 \%$; after 2 h: $13.9 \%$; after 24 h: $29.5 \%$; after 48 h: $22.3 \%$. Clavicular pectoralis: pre-test $=18.7 \%$; after $15 \mathrm{~min}: 14.5 \%$; after $2 \mathrm{~h}: 13.5 \%$; after $24 \mathrm{~h}: 27.1 \%$; after $48 \mathrm{~h}: 17.9 \%$. Triceps: pre-test $=14.9 \%$; after $15 \mathrm{~min}: 24.2 \%$; after $2 \mathrm{~h}: 17.9 \%$; after $24 \mathrm{~h}: 23.2 \%$; after 48 h: $24.7 \%$. Deltoid: pre-test $=11.1 \%$; after $15 \mathrm{~min}: 20.0 \%$; after $2 \mathrm{~h}: 3.44 \%$; after $24 \mathrm{~h}$ : $16.8 \%$; after 48 h: $23.2 \%$.

For the CWI recovery, the \%CV of the variables were: external chest: pre-test $=13.8 \%$; after 15 min: $17.3 \%$; after 2 h: $13.8 \%$; after 24 h: $22.1 \%$; after 48 h: $18.2 \%$. Clavicular pectoralis: pre-test $=11.9 \%$; after $15 \mathrm{~min}: 24.0 \%$; after $2 \mathrm{~h}$ : $15.8 \%$; after $24 \mathrm{~h}: 19.7 \%$; after 48 h: $18.1 \%$. Triceps: pre-test $=12.0 \%$; after 15 min: $20.0 \%$; after 2 h: $16.7 \%$; after 24 h: $14.9 \%$; after 48 h: $20.6 \%$. Deltoid: pre-test $=12.3 \%$; after 15 min: $9.1 \%$; after 2 h: $7.8 \%$; after 24 h: $16.7 \%$; after 48 h: $19.9 \%$.

The ICC between the recovery methods (passive, DN, and CWI) for each muscle was: external chest: pre-test: ICC $=0.33$ (95\% CI: $-0.07 ; 0.77, p=0.05)$; after $15 \mathrm{~min}: \mathrm{CCI}=0.06$ (95\% CI: $-0.26 ; 0.60, p=0.3$ ); after 2 h: CCI $=0.05$ (95\% CI: $-0.26 ; 0.59, p=0.3$ ); after 24 h: CCI $=-0.04$ (95\% CI: $-0.32 ; 0.49, p=0.5)$; after 48 h: ICC $=0.52$ (95\% CI: $0.09 ; 0.85$, $p=0.007)$. Clavicular pectoralis: pre-test: ICC $=0.19 ;(95 \%$ CI: $-0.18 ; 0.69, p=0.1)$; after 15 min: ICC $=-0.07(95 \%$ CI: $-0.33 ; 0.46, p=0.5)$; after 2 h: ICC $=0.12$ (95\% CI: $-0.22 ; 0.64$, $p=0.2)$; after $24 \mathrm{~h}$ : ICC $=0.04(95 \%$ CI: $-0.27 ; 0.58, p=0.3)$; after $48 \mathrm{~h}: \mathrm{ICC}=0.30(95 \% \mathrm{CI}$ : $-0.10 ; 0.76, p=0.07)$. Triceps: pretest $=$ ICC $=0.11(95 \%$ CI: 0.23; 0.64, $p=0.2)$; after $15 \mathrm{~min}$ : ICC $=0.24$ (95\% CI: $-0.14 ; 0.72, p=0.1)$; after 2 h: ICC $=0.22(95 \%$ CI: $-0.16 ; 0.71, p=0.1)$; after 24 h: ICC $=0.02(95 \%$ CI: $-0.28 ; 0.56, p=0.4)$; after 48 h: ICC $=0.40(95 \%$ CI: -0.01 ; $0.81, p=0.03)$. Deltoid: pre-test: ICC $=0.70$ (95\% CI: 0.34; 0.92, $p=0.0002)$; after $15 \mathrm{~min}$ : ICC $=0.03(95 \%$ CI: $-0.27 ; 0.57, p=0.3)$; after 2 h: ICC $=0.29(95 \%$ CI: $-0.11 ; 0.75, p=0.08)$; after 24 h: ICC $=0.00(95 \%$ CI: $-0.29 ; 0.54, p=0.4)$; after 48 h: ICC $=0.236$ (95\% CI: -0.15 ; $0.72, p=0.1$ ).

Pain pressure threshold was significantly affected by the recovery method for the pectoralis muscles $\left(\mathrm{F}=8.4, p \leq 0.003 ; \eta^{2} \mathrm{p}=0.51\right)$, but not for the deltoid muscle $(\mathrm{F}=2.9$, $\left.p=0.085 ; \eta^{2} p=0.26\right)$. A significant effect of time was found $\left(F=5.3, p<0.002 ; \eta^{2} p=0.40\right)$ for all muscles, together with a significant interaction effect $\left(F=5.2, p \leq 0.005 ; \eta^{2} p=0.39\right)$ on pain pressure threshold. Post-hoc comparisons revealed that pain pressure threshold increased significantly immediately after all implementations of recovery methods (15 min). However, the pain pressure threshold continued to decrease for all muscles, with the lowest measurement being noted $24 \mathrm{~h}$ after PR, after which it increased again. In DN, a similar development to PR was noted, but the decrease in pain pressure threshold decreased, in general, less than that after PR. After CWI, pain pressure stabilized after $15 \mathrm{~min}$ and significantly increased again after $2 \mathrm{~h}$ for the pectoralis sternal part (Figure 5).

In relation to Figure 5, for passive recovery, the $\% \mathrm{CV}$ of the variables were: external chest: pre-test $=11.7 \%$; after 15 min: $5.7 \%$; after 2 h: $11.9 \%$; after 24 h: $6.0 \%$; after 48 h: $3.0 \%$. Clavicular pectoral: pre-test $=9.8 \%$; after 15 min: $11.3 \%$; after $2 \mathrm{~h}: 4.5 \%$; after $24 \mathrm{~h}: 5.9 \%$; after 48 h: 8.4\%. Triceps: pre-test $=13.1 \%$; after $15 \mathrm{~min}: 10.2 \%$; after 2 h: 9.0\%; after $24 \mathrm{~h}$ : $6.8 \%$; after 48 h: $6.7 \%$. Deltoid: pre-test $=6.3 \%$; after 15 min: $7.6 \%$; after 2 h: $4.8 \%$; after $24 \mathrm{~h}$ $4.1 \%$; after 48 h: $4.7 \%$. 


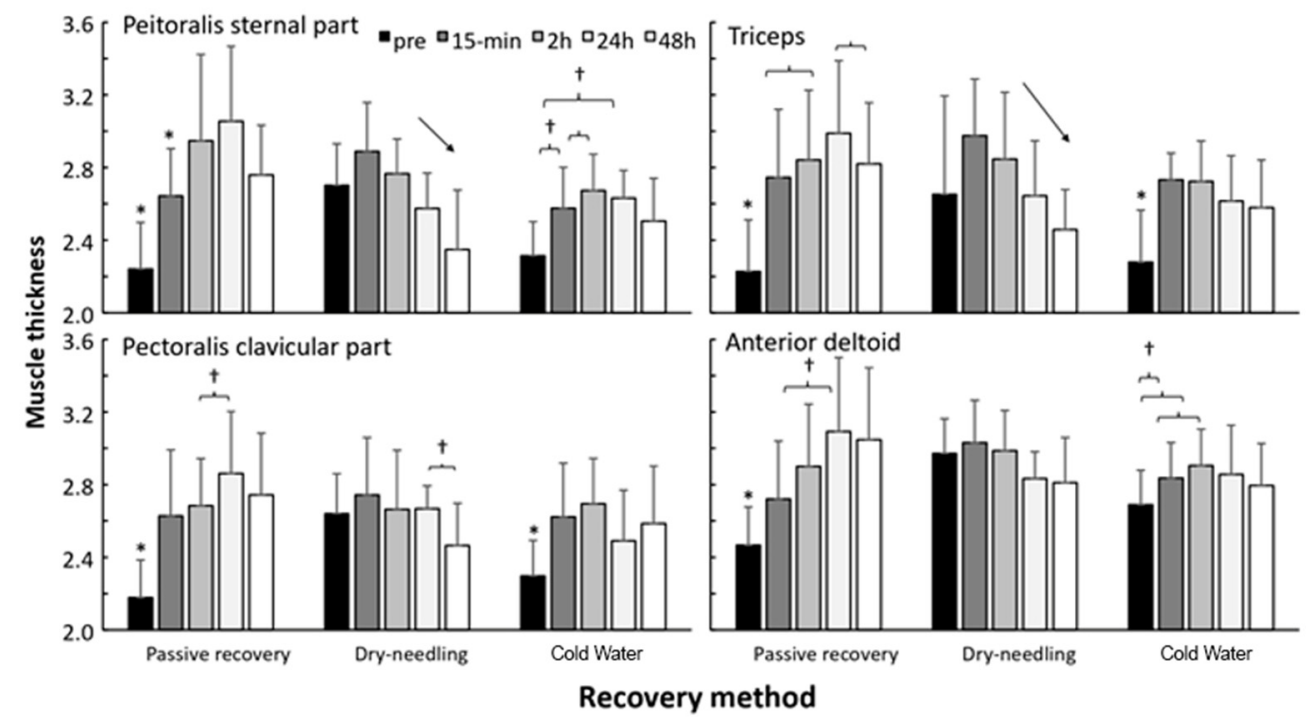

Figure 5. Mean $( \pm$ SEM) differences in muscle thickness measured with ultrasound before and after $15 \mathrm{~min}, 2 \mathrm{~h}, 24$, and $48 \mathrm{~h}$ exercise-induced muscle damage and recovery (passive, dry-needling, or coldwater immersion) protocol for triceps, pectoralis clavicular, sternal part, and anterior deltoid muscles. Muscle thickness $(\mathrm{cm}) .{ }^{*}$ indicates a significant difference with all other test occasions $(p<0.05)$. + indicates a significant difference between these two test occasions. $(p<0.05)$ indicates a significant change between these test moments for this protocol on a $p<0.05$ level.

For DN recovery, the $\% \mathrm{CV}$ of the variables were: external chest: pre-test $=8.6 \%$; after 15 min: $9.5 \%$; after $2 \mathrm{~h}: 68 \%$; after $24 \mathrm{~h}: 7.5 \%$; after $48 \mathrm{~h}: 14.4 \%$. Clavicular pectoralis: pre-test $=8.4 \%$; after $15 \mathrm{~min}: 11.9 \%$; after $2 \mathrm{~h}: 12.6 \%$; after $24 \mathrm{~h}: 4.2 \%$; after $48 \mathrm{~h}: 9.5 \%$. Triceps: pre-test $=21.4 \%$; after $15 \mathrm{~min}: 10.9 \%$; after $2 \mathrm{~h}: 13.5 \%$; after $24 \mathrm{~h}: 11.8 \%$; after 48 h: $9.1 \%$. Deltoid: pre-test $=6.4$; after 15 min: 7.8 ; after 2 h: $7.5 \%$; after 24 h $4.9 \%$; after 48 h: $9.0 \%$.

For the CWI recovery, the $\% \mathrm{CV}$ of the variables were: external chest: pre-test $=8.0 \%$; after 15 min: $8.8 \%$; after 2 h: $7.5 \%$; after 24 h: $5.5 \%$; after 48 h: $9.5 \%$. Clavicular pectoralis: pre-test $=8.4 \%$; after $15 \mathrm{~min}: 11.5 \%$; after $2 \mathrm{~h}: 9.4 \%$; after $24 \mathrm{~h}: 11.5 \%$; after $48 \mathrm{h:} 12.6 \%$. Triceps: pre-test $=13.0 \%$; after $15 \mathrm{~min}: 5.0 \%$; after $2 \mathrm{~h}: 8.2 \%$; after $24 \mathrm{~h}: 9.7 \%$; after $48 \mathrm{~h}$ : $10.4 \%$. Deltoid: pre-test $=6.9 \%$; after 15 min: $6.8 \%$; after 2 h: $6.9 \%$; after 24 h: $9.7 \%$; after 48 h: $8.4 \%$.

The ICC between the recovery methods (passive, DN, and CWI) for each muscle was: external chest: pre-test: ICC $=0.10$ (95\% CI: $-0.24 ; 0.63, p=0.2)$; after $15 \mathrm{~min}$ : ICC $=0.09$ (95\% CI: $-0.24 ; 0.62, p=0.3)$; after 2 h: ICC $=0.13$ (95\% CI: $-0.22 ; 0.65, p=0.2)$; after 24 h: ICC $=-0.25$ (95\% CI: $-0.41 ; 0.20, p=0.8)$; after 48 h: ICC $=0.00(95 \%$ CI: $-0.29 ; 0.54$, $p=0.4)$. Clavicular sinus: pre-test: ICC $=0.12(95 \% \mathrm{CI}:-0.23 ; 0.64, p=0.2)$; after $15 \mathrm{~min}$ : ICC $=0.39(95 \%$ CI: $-0.02 ; 0.80, p=0.03)$; after 2 h: ICC $=0.15(95 \%$ CI: $-0.21 ; 0.66, p=0.2)$; after 24 h: ICC $=0.02$ (95\% CI: $-0.28 ; 0.56, p=0.4)$; after 48 h: ICC $=0.525$ (95\% CI: 0.10 ; $0.86, p=0.007)$. Triceps: pre-test: ICC $=-0.01(95 \% \mathrm{CI}-0.30 ; 0.53, p=0.4)$; after $15 \mathrm{~min}$ : ICC $=0.32(95 \%$ CI: $-0.08 ; 0.77, p=0.06)$; after 2 h: ICC $=0.24(95 \%$ CI: $-0.15 ; 0.72, p=0.1)$; after 24 h: ICC $=-0.0$ (95\% CI: $-0.34 ; 0.43, p=0.6)$; after 48 h: ICC $=0.26$ (95\% CI: -0.13 ; $0.73, p=0.1)$. Deltoid: pre-test: ICC $=-0.16$ (95\% CI: $-0.37 ; 0.35, p=0.7)$; after $15 \mathrm{~min}$ : ICC $=-0.32$ (95\% CI: $-0.44 ; 0.06, p=0.9)$; after 2 h: ICC $=0.35$ (95\% CI: $-0.06 ; 0.78, p=0.05)$; after 24 h: ICC $=-0.02$ (95\% CI: $-0.30 ; 0.52, p=0.5)$; after 48 h: ICC $=0.04$ (95\% CI: -0.27 ; $0.58, p=0.3)$.

\section{Discussion}

To our knowledge, this study is the first to investigate the effects of different methods of recovery on Paralympic powerlifting athletes. This study aimed to evaluate the effects of 
three different post-training recovery methods on mechanical, biochemical, muscle edema, and pain indicators in Paralympic powerlifting athletes.

This study's important results are as follows: (1) Maximal force decreased from pretest to post-test after application of different recovery methods. (2) Only the DN increased IL-2 levels at different time points. (3) After DN, muscle thickness did not increase; however, after CWI, muscle thickness was higher after $15 \mathrm{~min}$ and $2 \mathrm{~h}$. (4) Pain pressure threshold reduced after applying the $\mathrm{DN}$ method.

The results show that the recovery methods can alter the MIF magnitude. A significant effect of the recovery method was found for MIF. The results revealed that the magnitude of MIF decreased compared to pretest values and the implementation of the different recovery methods. Both PR and DN increased to their respective baseline levels at 2 and $24 \mathrm{~h}$, whereas with cold-water immersion MIF increased from 2 to $24 \mathrm{~h}$ but reached $20 \%$ more force after $24 \mathrm{~h}$ than that at baseline level (Figure 2). It is difficult to explain these results. Some studies have assessed the effectiveness of CWI on muscle stiffness after strenuous exercise $[9,10,12,33]$. Although CWI reduces muscle pain $24 \mathrm{~h}$ after exercise, our study results suggest that CWI does not affect muscle thickness.

There is an increasing body of evidence that exercises, including the strength training exercise, can alter different cytokine plasma levels [34]. IL-2 is a cytokine signaling molecule in the immune system that regulates lymphocyte activities. It is part of the body's natural response to microbial infection that helps discriminate foreign ("non-self") cells from "self" cells (31). IL-4 induces differentiation of naive helper T cells to Th2 cells [34]. There has been growing interest among scientists to examine the immune system's behavioral response to exercise. Therefore, we investigated the role of exercise sessions on IL-2, IL-4, and TNF plasma levels. It was found that the recovery methods had a significant effect only on IL-2 at the tested time points. The results also demonstrated that CWI and DN methods increased IL-2 levels from 24 to $48 \mathrm{~h}$ more than that from 2 to $24 \mathrm{~h}$.

Historically, inflammation has been thought to be detrimental for recovery from exercise. However, it is now widely accepted that if tightly regulated, inflammatory responses are integral to muscle repair and regeneration [35]. The authors of different studies revealed that various cell types, including neutrophils, macrophages, mast cells, eosinophils, CD8 and T-regulatory lymphocytes, and adipogenic fibro progenitors pericytes, help facilitate muscle tissue regeneration [36,37]. However, more research is required to determine whether these cells respond to exercise-induced muscle damage. A large body of research has investigated the efficacy of physiotherapeutic, pharmacologic, and nutritional interventions for reducing the signs and symptoms of exercise-induced muscle damage, with mixed results [36-38].

Regarding muscle thickness, a significant effect of the recovery method on muscle thickness was noted. This study noticed that the muscle thickness increased mostly after PR in all muscles and remained elevated, whereas only the muscle thickness was significantly higher after $15 \mathrm{~min}$ and $2 \mathrm{~h}$ after CWI. After the DN method, muscle thickness did not increase significantly in any of the muscles, and after $2 \mathrm{~h}$, muscle thickness decreased significantly again in the major pectoralis muscle (Figure 3). Exercise seems to induce a continuous increase in elbow flexors' thickness from 24 to $96 \mathrm{~h}$ after strength training [39]. In our study, both DP and CWI reduced the effects of exercise on muscle thickness.

We also investigated the pain pressure threshold. Exercise sessions seemed to induce an elevation in the pain perception, which was significantly affected by the recovery method used for the pectoralis muscles, not for the deltoid muscles. The results also revealed that the pain pressure threshold increased significantly immediately after the implementation of all recovery methods $(15 \mathrm{~min})$. However, the pain pressure threshold continued to decrease for all muscles, with the lowest value occurring $24 \mathrm{~h}$ after PR and increasing after that. In the DN recovery method, a similar development as that in PR occurred, but the reduction in pain pressure threshold decreased, in general, less than that in PR. After CWI, pain pressure stabilized after $15 \mathrm{~min}$ and significantly increased after $2 \mathrm{~h}$ for the pectoralis clavicular part (Figure 4). 
An important aspect of our study is that these analyses were performed in a particular group of Paralympic athletes. On the one hand, these data provide new insights into recovery in high-level Paralympic athletes, whereas, on the other hand, interpretation of these data is difficult because of the lack of literature on this topic. Therefore, our study contributes to the area of sports science by shedding light on a particular group of Paralympic powerlifting athletes' adaptive responses to different recovery methods.

However, despite the relevance of the results, the present study has some limitations: (1) sample size; (2) a short period of experiment; and (3) the athletes' diet was not controlled during the study period. These limitations can interfere with the recovery process. Therefore, we suggest the inclusion of extra measurements across a prolonged period.

\section{Conclusions}

The strength training session was able to generate changes in metabolism, and different recovery methods contributed differently to the return of homeostasis in Paralympic powerlifting athletes. Muscle damage can be caused by metabolic, structural, and microvascular changes, with systemic and local effects. Because of the above, the results show that interventions alter some aspects of local recovery in edema and pain. However, there are still systemic effects.

It seems that cold water has a good recovery up to 24 and $48 \mathrm{~h}$ later and dry needling appears to be a good option for $24 \mathrm{~h}$ after the training session. In this sense, the work presents the effective dry needling methods for shorter-term recoveries and CWI presents itself as a good alternative for slightly shorter and longer recoveries.

Author Contributions: Conceptualization, W.Y.H.d.S. and F.J.A.; methodology, F.J.A., D.G.d.M., and R.V.d.T., software, P.F.d.A.-N., validation, A.C.M., L.F.L., and L.S.M.-B., formal analysis, N.D.G. and V.M.R., investigation, W.Y.H.d.S., F.J.A., and S.d.C.M., resources, É.L.M.V., data curation, F.J.A., R.V.d.T., É.L.M.V., J.V.-A., and A.N.-S., writing—original draft preparation, A.N.-S. and W.M.d.S.J., writing-review and editing, B.G.d.A.T.C. and W.M.d.S.J., visualization, D.G.d.M.; supervision, V.M.R., project administration, P.F.d.A.-N. All authors have read and agreed to the published version of the manuscript.

Funding: Victor Machado Reis and Nuno Domingos Garrido were funded by FCT-Fundação Portuguesa para a Ciência e Tecnologia (UID04045/2020).

Institutional Review Board Statement: The study was conducted according to the guidelines of the Declaration of Helsinki and approved by the Human Research Ethics Committee of the Federal University of Sergipe (UFS), CAEE: 79909917.0.0000.55.46 (date of approval: 7 May 2018).

Informed Consent Statement: Informed consent was obtained from all subjects involved in the study.

Data Availability Statement: The data that support this study can be obtained from the address www.ufs.br/GPEPS, Accessed on 20 February 2021.

Conflicts of Interest: The authors declare no conflict of interest.

\section{References}

1. Pastre, C.M.; Bastos, F.N.; Netto-Junior, J.; Vanderlei, L.C.M.; Hoshi, R.A. Post-exercise recovery methods: A systematic review. Braz. J. Sports Med. 2009, 15, 138-144.

2. Torres, R.; Ribeiro, F.; Duarte, A.J.; Cabri, J.M. Evidence of the physiotherapeutic interventions used currently after exerciseinduced muscle damage: Systematic review and meta-analysis. Phys. Ther. Sport 2012, 13, 101-114. [CrossRef]

3. Wilcock, I.M.; Cronim, J.B.; Hing, W.A. Physiological response to water immersion: A method for sport recovery? Sports Med. 2006, 36, 747-765. [CrossRef]

4. Barnett, A. Using recovery modalities between training sessions in elite athletes: Does it help? Sports Med. 2006, 36, 781-796. [CrossRef]

5. Paz, Â.A.; Aidar, F.J.; de Matos, D.G.; de Souza, R.F.; van den Tillaar, R.; Reis, V.M. Comparison of Post-Exercise Hypotension Responses in Paralympic Powerlifting Athletes after Completing Two Bench Press Training Intensities. Medicina 2020, 56, 156. [CrossRef]

6. Budgett, R.; Hiscock, N.; Arida, R.; Castell, L.M. The effects of the 5-HT2C agonist m-chlorophenylpiperazine on elite athletes with unexplained underperformance syndrome (overtraining). Br. J. Sports Med. 2010, 44, 470. [CrossRef] 
7. Dupuy, O.; Douzi, W.; Theurot, D.; Bosquet, L.; Dugué, B. An evidence-based approach for choosing post-exercise recovery techniques to reduce markers of muscle damage, soreness, fatigue, and inflammation: A systematic review with meta-analysis. Front. Physiol. 2018, 9, 403. [CrossRef] [PubMed]

8. Banfi, G.; Lombardi, G.; Colombini, A.; Melegati, G. Whole-body cryotherapy in athletes. Sports Med. 2010, 40, 509-517. [CrossRef]

9. Halson, S.L.; Quod, M.J.; Martin, D.T.; Gardner, A.S.; Ebert, T.R.; Laursen, P.B. Physiological responses to cold water immersion following cycling in the heat. Inter. J. Sports Physiol. Perform. 2008, 3, 331-346. [CrossRef]

10. Versey, N.G.; Halson, S.L.; Dawson, B.T. Water Immersion Recovery for Athletes: Effect on Exercise Performance and Practical Recommendations. Sports Med. 2013, 43, 1101-1130. [CrossRef]

11. An, J.; Lee, I.; Yi, Y. The Thermal Effects of Water Immersion on Health Outcomes: An Integrative Review. Int. J. Environ. Res. Public Health 2019, 16, 1280. [CrossRef]

12. Machado, A.F.; Ferreira, P.H.; Micheletti, J.K.; de Almeida, A.C.; Lemes, Í.R.; Vanderlei, F.M. Can Water Temperature and Immersion Time Influence the Effect of Cold Water Immersion on Muscle Soreness? A Systematic Review and Meta-Analysis. Sports Med. 2016, 46, 503-514. [CrossRef]

13. Vieira, A.; Siqueira, A.F.; Ferreira-Junior, J.B.; do Carmo, J.; Durigan, J.L.Q.; Blazevich, A.; Bottaro, M. The Effect of Water Temperature during Cold-Water Immersion on Recovery from Exercise-Induced Muscle Damage. Int. J. Sports Med. 2016, 37, 937-943. [CrossRef]

14. Hsieh, Y.L.; Kao, M.J.; Kuan, T.S.; Chen, S.M.; Chen, T.J.; Hong, C.Z. Dry needling to a key myofascial tigger point may reduce the irrritability of satellite MTrPs. Am. J. Phys. Med. Rehabil. 2007, 86, 397-403. [CrossRef]

15. Tsai, C.T.; Hsieh, L.S.; Kuan, T.S.; Kao, M.J.; Chou, L.W.; Hong, C.Z. Remote effects of dry needling on the irritability of the myofascial trigger point in the upper trapezius muscle. Am. J. Phys. Med. Rehabil. 2010, 89, 133-140. [CrossRef]

16. Chaudhry, F.A. Effectiveness of dry needling and high-volume image-guided injection in the management of chronic midportion Achilles tendinopathy in adult population: A literature review. Eur. J. Orthop. Surg. Traumatol. 2017, 27, 441-448. [CrossRef] [PubMed]

17. Hyldahl, R.D.; Peake, J.M. Combining cooling or heating applications with exercise training to enhance performance and muscle adaptations. J. Appl. Physiol. 2020, 129, 353-365. [CrossRef] [PubMed]

18. Fraga, G.S.; Aidar, F.J.; de Matos, D.G.; Marçal, A.C.; Santos, J.L.; Reis, V.M. Effects of Ibuprofen Intake in Muscle Damage, Body Temperature and Muscle Power in Paralympic Powerlifting Athletes. Int. J. Environ. Res. Public Health 2020, $17,5157$. [CrossRef] [PubMed]

19. Sampaio, C.R.; Aidar, F.J.; Ferreira, A.R.P.; Marçal, A.C.; Matos, D.G.; Reis, V.M. Can Creatine Supplementation Interfere with Muscle Strength and Fatigue in Brazilian National Level Paralympic Powerlifting? Nutrients 2020, 12, 2492. [CrossRef]

20. Sarshin, A.; Naderi, A.; da Cruz, C.J.G.; Feizolahi, F.; Forbes, S.C.; Earnest, C.P. The effects of varying doses of caffeine on cardiac parasympathetic reactivation following an acute bout of anaerobic exercise in recreational athletes. J. Int. Soc. Sports Nutr. 2020, 17, 44. [CrossRef]

21. International Paralympic Comite (IPC). Rules. Official Website of IPC Powerlifting. Available online: http://www.paralympic. org/powerlifting/about (accessed on 10 January 2020).

22. Fleck, S.J.; Kraemer, W. Designing Resistance Training Programs, 4E; Human Kinetics: Champaign, IL, USA, 2014.

23. Austin, D.; Mann, B. Powerlifting; Human Kinetics: Champaign, IL, USA, 2012.

24. Bonsu, B.; Terblanche, E. The training and detraining effect of high-intensity interval training on post-exercise hypotensionin young overweight/obese women. Eur. J. Appl. Physiol. 2016, 116, 77-84. [CrossRef]

25. Gattie, E.; Joshua, A.; Snodgrass, S. The Effectiveness of Trigger Point Dry Needling for Musculoskeletal Conditions by Physical Therapists: A Systematic Review and Meta-analysis. J. Orthop. Sports Phys. Ther. 2017, 47, 133-149. [CrossRef]

26. Yasuda, T.; Fujita, S.; Ogasawara, R.; Sato, Y.; Abe, T. Effects of low intensity bench press training with restricted arm muscle blood flow on chest muscle hypertrophy: A pilot study. Clin. Physiol. Funct. Imaging 2010, 30, 338-343. [CrossRef]

27. Kosek, E.; Ekholm, J.; Hansson, P. Pressure pain thresholds in different tissues in one. Scand. J. Rehabil. Med. 1999, $31,89-93$.

28. Lixandrão, M.E.; Ugrinowitsch, C.; Bottaro, M.; Laurentino, G.C.; Libardi, C.A. Vastus lateralis muscle cross-sectional area ultrasonography validity for image fitting in humans. J. Strength Cond. Res. 2014, 28, 3293-3297. [CrossRef]

29. Janeway, C.A.; Traver, P., Jr.; Walport, M.; Shlomchik, M.J. Immunobiology, The Immune System in Health and Disease, 5th ed.; Garland Science: New York, NY, USA, 2001.

30. Moldoveanu, A.I.; Shephard, R.J.; Shek, P.N. Exercise elevates plasma levels but not gene expression of IL-1b, IL-6, and TNF- $\alpha$ in blood mononuclear cells. J. Appl. Physiol. 2000, 89, 1499-1504. [CrossRef]

31. Kizaki, T.; Takemasa, T.; Sakurai, T.; Izawa, T.; Hanawa, T.; Kamiya, T.; Haga, S.; Imaizumi, K.; Ohno, H. Adaptation of macrophages to exercise training improves innate immunity. Biochem. Biophys. Res. Commun. 2008, 372, 152-156. [CrossRef]

32. Cohen, J. Statistics a power primer. Psychol. Bull. 1992, 112, 155-159. [CrossRef]

33. Pinto, J.; Rocha, P.; Torres, R. Cold-Water Immersion Has No Effect on Muscle Stiffness after Exercise-Induced Muscle Damage. Clin. J. Sport Med. J. Can. Acad. Sport Med. 2018, 30, 533-538. [CrossRef] [PubMed]

34. Fortunato, A.K.; Pontes, W.M.; De Souza, D.M.S.; Prazeres, J.S.F.; Santos, J.M.M.; da Silva, A.N. Strength training session induces important changes on physiological, immunological, and inflammatory biomarkers. J. Immunol. Res. 2018. [CrossRef]

35. Peake, J.M.; Neubauer, O.; Della Gatta, P.A.; Nosaka, K. Muscle damage and inflammation during recovery from exercise. J. Appl. Physiol. 2017, 122, 559-570. [CrossRef] [PubMed] 
36. Deyhle, M.R.; Gier, A.M.; Evens, K.C.; Eggett, D.L.; Parcell, A.C.; Hyldahl, R.D. Skeletal muscle inflammation following repeated bouts of lengthening contractions in humans. Front. Physiol. 2016, 6, 424. [CrossRef] [PubMed]

37. Marklund, P.; Mattsson, C.M.; Wåhlin-Larsson, B.; Lindvall, B.; Lindvall, L.; Kadi, F. Extensive inflammatory cell infiltration in human skeletal muscle in response to an ultraendurance exercise bout in experienced athletes. J. Appl. Physiol. 2013, 114, 66-72. [CrossRef]

38. Marcucci-Barbosa, L.S.; Martins-Junior, F.; Lobo, L.F.; Morais, M.G.; Moreira, J.M.; Nunes-Silva, A. 10 km running race induces an elevation in the plasma myokine level of nonprofessional runners. Sport Sci. Health 2019, 16, 1-9. [CrossRef]

39. Neves, E.B.; Moreira, T.R.; Lemos, R.; Vilaça-Alves, J.; Rosa, C.; Reis, V.M. Using skin temperature and muscle thickness to assess muscle response to strength training. Braz. J. Sports Med. 2015, 21, 350-354. [CrossRef] 